ARTIKEL RISET

\title{
Efektivitas Modul Larutan Elektrolit dan Nonelektrolit berorientasi Chemistry Triangle terhadap Hasil Belajar Peserta Didik
}

\section{The Effectiveness of Electrolyte and Nonelectrolyte Solution Module oriented to the Chemistry Triangle towards Students' Learning Outcomes}

\author{
Hardeli $^{*}$ and A Citra ${ }^{1}$ \\ 1 Pendidikan Kimia, Universitas Negeri Padang, \\ Jl. Prof. Dr. Hamka, Air Tawar Barat, Padang Utara, Sumatera Barat, Indonesia 25171 \\ *hardeli1@yahoo.com
}

\section{ARTICLE INFO \\ Received on: \\ 24 June 2020 \\ Revised till: \\ 14 July 2020 \\ Accepted on: \\ 17 July 2020 \\ Publisher version published on:}

28 February 2021

\begin{abstract}
Electrolyte and nonelectrolyte solution module oriented to chemistry triangle have been experimented using a randomized pretest-posttest control group design. This study goals to reveal the level of effectiveness of electrolyte and nonelectrolyte solution module oriented to chemistry triangle on learning outcomes of class X MIA at SMAN 15 Padang. Research instruments is multiple choice tests that have been valid, reliable, differentiating power, and indexing difficulties that could measure student learning outcomes. The level of effectiveness of electrolyte and nonelectrolyte solution module oriented to chemistry triangle is known through the $N$-gain test. $N$-gain test results with a value of $g=0.46$ states that electrolyte and nonelectrolyte solution module oriented to chemistry triangle is effective in improving student learning outcomes on medium criteria.
\end{abstract}

\section{KEYWORDS}

Chemistry Triangle, Effectiveness, Learning Outcomes, Module

\begin{abstract}
ABSTRAK
Modul larutan elektrolit dan nonelektrolit yang berorientasi chemistry triangle telah diuji coba menggunakan desain kelompok kontrol pretest-posttest acak. Penelitian ini bertujuan untuk mengungkapkan tingkat efektivitas modul larutan elektrolit dan nonelektrolit berorientasi chemistry triangle terhadap hasil pembelajaran kelas X MIA di SMAN 15 Padang. Instrumen penelitian adalah tes pilihan ganda yang telah valid, andal, berdiferensiasi, dan berindeks kesukaran yang dapat mengukur hasil belajar peserta didik. Tingkat efektivitas modul larutan elektrolit dan nonelektrolit berorientasi chemistry triangle diketahui melalui uji $N$-gain. Hasil uji $N$-gain dengan nilai g $=0,46$ menyatakan bahwa modul larutan elektrolit dan nonelektrolit berorientasi chemistry triangle efektif dalam meningkatkan hasil belajar siswa pada kriteria sedang.
\end{abstract}

KATA KUNCI

Chemistry Triangle, Efektivitas, Hasil Belajar, Modul 


\section{PENDAHULUAN}

Kualitas peserta didik sangat berpengaruh dalam kemajuan dunia saat ini. Kualitas peserta didik diketahui dari evaluasi terhadap hasil yang didapatkan dari pembelajaran ${ }^{[1]}$. Hasil belajar mengacu pada taksonomi Bloom terkait pada kemampuan psikomotor, kognitif, dan afektif. Ranah kognitif merupakan perspektif terkait hasil belajar inteligensi. Ranah afektif mencakup perilaku peserta didik selama kegiatan belajar. Keterampilan peserta didik pada kegiatan belajar dilihat pada ranah psikomotor ${ }^{[2]}$. Pembelajaran yang diterima akan memengaruhi kualitas peserta didik. Pembelajaran optimal jika sumber belajar sesuai dengan kebutuhan serta karakteristik pendidikan ${ }^{[3]}$. Tidak optimalnya pemanfaatan sumber belajar menjadi salah satu penyebab buruknya kualitas pembelajaran karena peserta didik belajar tidak sesuai bidangnya dan tidak memiliki pengetahuan aktual berupa akselerasi teknologi dan seni ${ }^{[4]}$.

Larutan elektrolit dan nonelektrolit merupakan salah satu contoh materi kimia yang berkonsep abstrak. Konsep abstrak menjadikan peserta didik kesulitan dan kurang bersemangat saat mempelajari $\operatorname{kimia}^{[5]}$. Modul dinilai relevan digunakan dalam pembelajaran karena dapat disesuaikan dengan karakteristik pembelajaran yang ditata secara sistematis dan menarik mencakup isi materi, metode dan evaluasi yang dapat digunakan secara mandiri ${ }^{[6]}$.

Hasil distribusi angket kepada 30 peserta didik kelas XI di SMAN 15 Padang memberikan bukti bahwa: (1) bahan ajar berupa buku paket yang digunakan tidak mencakup tiga level pembelajaran kimia; (2) $78 \%$ peserta didik menganggap materi kimia cukup sulit. Pembelajaran kimia umumnya dibatasi pada dua tingkat pemodelan, yaitu makro dan simbolik. Peserta didik diharapkan dapat menyatukan sendiri ilustrasi singkat di buku tanpa tuntunan guru untuk mempelajari level submikro ${ }^{[7]}$. Kesulitan mempelajari kimia yang diungkapkan peserta didik SMAN 15 Padang diduga karena belum menerapkan sumber belajar yang relevan yaitu modul dan pembelajaran pada tiga level (chemistry triangle).

Adanya pengembangan modul larutan elektrolit dan nonelektrolit berorientasi chemistry triangle bertujuan agar dapat menunjang karakteristik pembelajaran kimia yang bersifat abstrak dan mengurangi kesulitan belajar. Modul ini dikembangkan sesuai model Plomp dengan hasil tingkat validitas dan praktikalitas tinggi ${ }^{[8]}$. Hal ini karena pembelajaran chemistry triangle mencakup tingkatan aspek simbol, submikro, dan makro ${ }^{[9]}$.

Representasi aspek makro terkait pada pengamatan absolut dengan jelas seperti pergantian warna, suhu, $\mathrm{pH}$ larutan, serta terbentuknya gas dan endapan $^{[7]}$. Representasi submikro terkait fenomena yang tidak absolut (abstrak) misalnya elektron, molekul, dan atom ${ }^{[10]}$. Level submikro merupakan aspek paling kompleks disebabkan peserta didik dituntut agar berpikir abstrak ${ }^{[11]}$. Representasi simbolik berkaitan dengan penggunaan lambang kimia, rumus, persamaan, model dan animasi untuk melambangkan zat ${ }^{[12]}$. Keterkaitan antar level chemistry triangle disajikan pada Gambar 1.

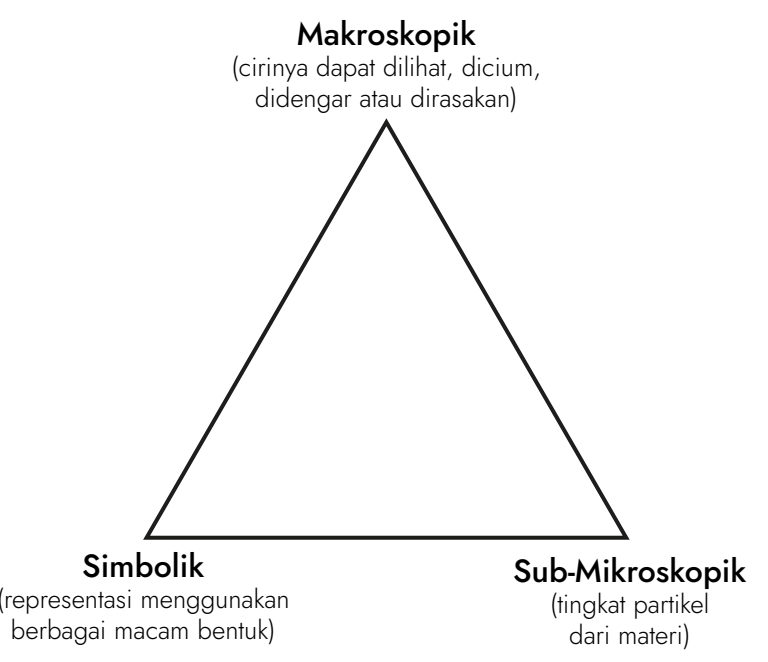

Gambar 1. Segitiga Pemahaman Johnstone ${ }^{[10]}$.

Modul larutan elektrolit dan nonelektrolit berorientasi chemistry triangle belum melalui uji efektivitas sehingga belum memenuhi kriteria sumber belajar yang baik. Sumber belajar yang baik harus memenuhi kriteria valid, praktis, dan efektif agar menghasilkan pembelajaran optimal[13]. Efektivitas ialah kesesuaian tujuan dengan hasil yang diraih dengan kata lain berhasil guna. Modul efektif jika evaluasi hasil belajar peserta didik menunjukkan pencapaian tujuan pembelajaran yang diharapkan ${ }^{[14-15]}$.

Keefektifan sumber belajar dapat diketahui melalui pengukuran hasil belajar sebelumnya dari kelompokyang sama atau kelompok lain dengan hasil belajar terkini untuk pembanding. Pembelajaran efektif bila hasil belajar membaik dan meningkat seperti penambahan pengetahuan, perbaikan sikap, dan keterampilan yang dimiliki ${ }^{[16]}$. Oleh karena itu, pengeksperimenan modul berorientasi chemistry triangle penting dilakukan untuk mengungkap tingkat efektivitasnya terhadap hasil belajar. Keberhasilan eksperimen ini akan membantu mengatasi kesulitan peserta didik mempelajari konsep abstrak kimia dan meningkatkan hasil belajar sehingga membentuk peserta didik yang lebih berkualitas.

\section{METODE}

Penelitian untuk mengetahui tingkat efektivitas modul larutan elektrolit dan nonelektrolit berorientasi chemistry triangle terhadap peningkatan hasil belajar peserta didik dieksperimen dengan skema randomized pretest-posttest control group. Semua peserta didik kelas X MIA SMAN 15 Padang TA 2019/2020 menjadi populasi pada penelitian yang dijalankan. Sampel dipilah dengan teknik simple random karena populasi berdistribusi normal dan homogen. Dari pengambilan sampel kelas X MIA 2 terpilih sebagai kelas eksperimen yang belajar dengan modul larutan elektrolit 
dan nonelektrolit berorientasi chemistry triangle. Sedangkan kelas X MIA 4 menjadi kelas kontrol yang tidak menjalankan pembelajaran dengan modul larutan elektrolit dan nonelektrolit berorientasi chemistry triangle melainkan tetap dengan buku paket yang biasa digunakan oleh guru kimia SMAN 15 Padang ${ }^{[17]}$. Skema penelitian lebih lanjut digambarkan pada Tabel 1.

Tabel 1. Skema penelitian.

\begin{tabular}{c|c|c} 
& Eksperimen & Kontrol \\
\hline Pretest & $\mathrm{P}_{1}$ & $\mathrm{P}_{3}$ \\
\hline Perlakuan & $\mathrm{X}$ & - \\
\hline Posttest & $\mathrm{P}_{2}$ & $\mathrm{P}_{4}$
\end{tabular}

Instrumen penelitian untuk menguji hasil belajar ialah soal pilihan ganda sebanyak 20 butir yang telah memenuhi kriteria daya pembeda, valid, reliabel, dan berindeks kesukaran. Data hasil belajar kedua kelas sampel selanjutnya dianalisis untuk mengetahui tingkat efektivitas melalui persamaan $N$-gain, yang dijelaskan pada Persamaan 1 serta Persamaan 2 berikut:

$$
\begin{aligned}
& \mathrm{N}-\text { gain }=\frac{\% \text { tes akhir }-\% \text { tes awal }}{\text { nilai maksimal }-\% \text { tes awal }} \ldots \text { Persamaan } 1 \\
& g=\frac{\sum N-\text { gain peserta didik }}{\text { jumlah peserta didik }} \ldots \text { Persamaan } 2
\end{aligned}
$$

Poin $N$-gain yang diperoleh disesuaikan dengan kategori $N$-gain untuk menentukan tingkat keefektifan modul larutan elektrolit dan nonelektrolit berorientasi chemistry triangle. Kriteria uji $N$-gain ditampilkan pada Tabel 2.

Tabel 2. Kriteria $N$-gain ${ }^{[18]}$.

\begin{tabular}{c|c}
$\boldsymbol{N}$-Gain & Kategori \\
\hline $\mathrm{g} \leqslant 0,3$ & Rendah \\
\hline $0,7>\mathrm{g}>0,3>$ & Sedang \\
\hline $\mathrm{g} \geqslant 0,7$ & Tinggi
\end{tabular}

Keefektifan modul larutan elektrolit dan nonelektrolit berorientasi chemistry triangle juga disesuaikan dengan pemahaman peserta didik dalam menjawab pertanyaan Lembar Kegiatan dan Lembar Kerja modul larutan elektrolit dan nonelektrolit berorientasi chemistry triangle. Kategori pemahaman peserta didik terkait efektivitas modul larutan elektrolit dan nonelektrolit berorientasi chemistry triangle mengacu pada Tabel 3 dan telah dimodifikasi sesuai kebutuhan.
Tabel 3. Hubungan efektivitas modul dan pemahaman peserta didik dalam pengerjaan Lembar Kegiatan dan Lembar Kerja ${ }^{[19]}$.

\begin{tabular}{c|c|c} 
Rentang & Kategori & Kesimpulan \\
\hline $81-100$ & $\begin{array}{c}\text { Sangat } \\
\text { Tinggi }\end{array}$ & Sangat Efektif \\
\hline $61-80$ & Tinggi & Efektif \\
\hline $41-60$ & $\begin{array}{c}\text { Cukup } \\
\text { Tinggi }\end{array}$ & Cukup Efektif \\
\hline $21-40$ & Rendah & Kurang Efektif \\
\hline$\geqslant 20$ & $\begin{array}{c}\text { Sangat } \\
\text { Rendah }\end{array}$ & Tidak Efektif
\end{tabular}

Kebenaran hasil analisis n-gain diketahui melalui pengujian hipotesis penelitian dengan teknik tertentu. Teknik pengujian hipotesis bergantung pada kenormalan dan kehomogenan data hasil penelitian. Jika data hasil penelitian homogen dan normal maka diuji dengan Persamaan 3, namun jika data hasil penelitian normal tetapi tidak homogen maka gunakan Persamaan $4^{[20]}$.

$$
\begin{aligned}
& t=\frac{\bar{x}_{1}-\bar{x}_{2}}{S \sqrt{\frac{1}{n_{1}}+\frac{1}{n_{2}}}} \quad \ldots \text { Persamaan } 3 \\
& t^{\prime}=\frac{\overline{x_{1}}-\overline{x_{2}}}{\sqrt{\frac{s_{1}{ }^{2}}{n_{1}}+\frac{s_{2}{ }^{2}}{n_{2}}}} \ldots \text { Persamaan } 4
\end{aligned}
$$

Hipotesis dari penelitian ini adalah Persamaan 5 dan Persamaan 6 berikut:

$$
\begin{aligned}
& \mathrm{H}_{0}=\mu_{1} \leqslant \mu_{2} \ldots \text { Persamaan } 5 \\
& \mathrm{H}_{1}=\mu_{1}>\mu_{2} \ldots \text { Persamaan } 6
\end{aligned}
$$

$\mathrm{H}_{0}$ menyatakan bahwa modul larutan elektrolit dan nonelektrolit berorientasi chemistry triangle tidak efektif meningkatkan hasil belajar peserta didik. Di sisi lain, $\mathrm{H}_{1}$ menyatakan bahwa modul larutan elektrolit dan nonelektrolit berorientasi chemistry triangle efektif meningkatkan hasil belajar peserta didik. Dimana, $\mu_{1}$ dan $\mu_{2}$ berturut-turut ialah selisih posttest-pretest eksperimen dan kelas kontrol.

\section{HASIL DAN DISKUSI}

\subsection{Hasil Penelitian}

Peserta didik di tiap kelas sampel melalui pretest dan posttest untuk mengetahui hasil yang didapat dari masing perlakuan yang diterima. Pretest berguna mencari tahu kemampuan dasar peserta didik. Posttest dilaksanakan agar pemahaman peserta didik terhadap materi yang dipelajari dapat diketahui. Poin pretest dan posttest peserta didik dituangkan pada Tabel 4 . 
Tabel 4. Hasil Pretest-Posttest Peserta Didik.

\begin{tabular}{c|c|c} 
& Eksperimen & Kontrol \\
\hline $\mathrm{n}$ & 35,00 & 35,00 \\
\hline Pretest & 23,86 & 59,43 \\
\hline Posttest & 25,86 & 55,29 \\
\hline
\end{tabular}

\subsubsection{Uji N-gain}

Tes $N$-gain berfungsi untuk menentukan tingkat efektivitas modul larutan elektrolit dan nonelektrolit berorientasi chemistry triangle. Hasil penafsiran dengan kriteria $N$-gain pada keadaan tinggi, sedang, ataupun rendah dijadikan pertimbangan untuk penggunaan kembali pada kegiatan pembelajaran pada skala yang lebih luas. Hasil uji $N$-gain ditampilkan pada Tabel 5 .

Tabel 5. Hasil Uji $N$-gain.

\begin{tabular}{c|c|c} 
& Eksperimen & Kontrol \\
\hline $\mathrm{n}$ & 35,00 & 35,00 \\
\hline Pretest & 23,86 & 59,43 \\
\hline Posttest & 25,86 & 55,29 \\
\hline N-gain & 0,46 & 0,40
\end{tabular}

\subsubsection{Uji Normalitas}

Data berdistribusi normal merupakan pertimbangan penentuan cara pengujian hipotesis. Normalitas data kelas sampel diuji menggunakan uji Liliefors. Data terdistribusi normal pada saat nilai $\mathrm{L}_{\text {hitung }}<\mathrm{L}_{\text {tabel }}$. Hasil uji kenormalan data ditampilkan pada Tabel 6 .

Tabel 6. Uji Normalitas Posttest-Pretest.

\begin{tabular}{c|c|c} 
& A & B \\
\hline$\alpha$ & \multicolumn{2}{|c}{0,05} \\
\hline $\mathrm{L}_{\text {hitung }}$ & 0,0969 & 0,106 \\
\hline $\mathrm{L}_{\text {tabel }}$ & \multicolumn{2}{|c}{0,148} \\
\hline Keputusan & Normal & Normal
\end{tabular}

\subsubsection{Uji Homogenitas}

Homogenitas data diuji untuk menentukan kehomogenan varian data kelas sampel. Apabila varian data yang diperoleh homogen, maka kesalahan dalam generalisasi kesimpulan hasil penelitian dapat diperkecil. Homogenitas data diuji menggunakan uji F. Varian data homogen saat nilai $\mathrm{F}_{\text {hitung }}<\mathrm{F}_{\text {tabel }}$. Hasil pengecekan homogenitas data ditampilkan pada Tabel 7 .
Tabel 7. Uji Homogenitas Pretest-Posttest.

\begin{tabular}{c|c|c} 
& $\mathbf{A}$ & $\mathbf{B}$ \\
\hline $\mathrm{N}$ & 35,00 & 35,00 \\
\hline $\mathrm{S}^{2}$ & 311,349 & 151,964 \\
\hline $\mathrm{F}_{\text {hitung }}$ & \multicolumn{2}{|c}{2,235} \\
\hline $\mathrm{F}_{\text {tabel }}$ & \multicolumn{2}{|c}{1,772} \\
\hline Keterangan & \multicolumn{2}{|c}{ Tidak Homogen }
\end{tabular}

\subsubsection{Uji Hipotesis (Uji t')}

Pengujian hipotesis bertujuan untuk menentukan apakah hipotesis penelitian dapat diterima atau ditolak. Pengaplikasian uji t' dilatarbelakangi oleh data hasil pretest-posttest peserta didik yang berdistribusi normal namun tidak homogen. Hipotesis diterima dengan syarat $\mathrm{H}_{0}$ ditolak jika $t \geq \frac{w_{1} t_{1}+w_{2} t_{2}}{w_{1}+w_{2}}$. Keputusan dari pengujian tersebut ialah tolak $\mathrm{H}_{0}$ akibat nilai $\mathrm{t}_{\text {hitung }}(4,20)>$ $\mathrm{t}_{\text {tabel }}(1,667)$. Hipotesis yang diterima adalah modul larutan elektrolit dan nonelektrolit berorientasi chemistry triangle efektif meningkatkan hasil belajar peserta didik kelas X MIA SMAN 15 Padang. Hasil uji t' ditampilkan pada Tabel 8 .

Tabel 8. Hasil Uji Hipotesis t'.

\begin{tabular}{c|c|c} 
& A & B \\
\hline $\bar{X}$ & 35,57 & 29,57 \\
\hline $\mathrm{S}^{2}$ & 43,28 & 27,92 \\
\hline $\mathrm{t}^{\prime}$ & \multicolumn{2}{|c}{4,20} \\
\hline$w_{1} t_{1}+w_{2} t_{2}$ & \multicolumn{2}{|c}{1,667} \\
\hline$w_{1}+w_{2}$ & \multicolumn{2}{|c}{1,667} \\
\hline $\mathrm{t}_{\text {tabel }}$ & \multicolumn{2}{|c}{ Tolak $\mathrm{H}_{0}$}
\end{tabular}

\subsubsection{Analisis Lembar Kegiatan dan Lembar Kerja Modul}

Analisis Lembar Kegiatan dan Lembar Kerja ditujukan untuk mengetahui kesesuaian tingkat pemahaman peserta didik dengan tingkat efektivitas modul. Kategori yang diberikan disesuaikan dengan Tabel 3. Hasil analisis Lembar Kegiatan dan Lembar Kerja dapat dilihat pada Tabel 9 dan Tabel 10.

Tabel 9. Hasil Analisis Lembar Kegiatan.

\begin{tabular}{c|c|c} 
Lembar Kegiatan & $\begin{array}{c}\text { Rerata } \\
\text { nilai }\end{array}$ & Kategori \\
\hline 1 & 85,71 & Sangat Tinggi \\
\hline 2 & 56,89 & Cukup Tinggi \\
\hline 3 & 65,29 & Tinggi \\
\hline 4 & 56,43 & Cukup Tinggi \\
\hline Rata-rata & $\mathbf{6 6 , 0 8}$ & Tinggi
\end{tabular}


Tabel 10. Hasil Analisis Lembar Kerja.

\begin{tabular}{c|c|c} 
Lembar Kegiatan & $\begin{array}{c}\text { Rerata } \\
\text { nilai }\end{array}$ & Kategori \\
\hline 1 & 61,90 & Tinggi \\
\hline 2 & 50,50 & Cukup Tinggi \\
\hline 3 & 53,50 & Cukup Tinggi \\
\hline 4 & 47,05 & Cukup Tinggi \\
\hline Rata-rata & $\mathbf{5 2 , 9 0}$ & Cukup Tinggi
\end{tabular}

\subsection{Diskusi}

Hasil pretest-posttest menunjukkan adanya peningkatan hasil belajar berdasar pada Tabel 4. Nilai pretest peserta didik kelas eksperimen beranjak naik dari 23,86 ke 59,43. Kelas kontrol pun mengalami hal serupa, dari 25,86 menuju 55,29. Adanya peningkatan tersebut menandakan bahwa modul larutan elektrolit dan nonelektrolit berorientasi chemistry triangle yang digunakan kelas eksperimen dan buku paket yang digunakan kelas kontrol efektif dalam mencapai tujuan pembelajaran. Tingkat keefektifan tersebut selanjutnya diketahui melalui uji $\mathrm{N}$-gain. Nilai $\mathrm{N}$-gain kelas eksperimen adalah 0,46 sedangkan kelas kontrol memperoleh nilai 0,40 . Meskipun keduanya berada pada kategori sedang, namun kelas eksperimen tetap memiliki skor $N$-gain lebih tinggi. Hal ini menjadikan modul larutan elektrolit dan nonelektrolit berorientasi chemistry triangle lebih efektif dalam meningkatkan hasil belajar peserta didik.

Hasil uji hipotesis juga membuktikan bahwa modul larutan elektrolit dan nonelektrolit berorientasi chemistry triangle efektif meningkatkan hasil belajar peserta didik. Keputusan tersebut diambil karena diterimanya $H_{1}$. Nilai $t_{\text {hitung }}(4,20)>$ nilai $t_{\text {tabel }}(1,667)$ sehingga $\mathrm{H}_{0}$ ditolak. Modul chemistry triangle lebih disukai peserta didik karena terdapat gambargambar berwarna dan soal-soal yang dapat melatih kemampuannya. Modul kimia berorientasi chemistry triangle ditujukan agar pemahaman peserta didik terhadap konsep-konsep abstrak beranjak maju karena digambarkan secara detail ${ }^{[21]}$.

Chemistry triangle membutuhkan pengetahuan peserta didik terkait pengalaman dan pengajaran yang telah didapatkan. Kesulitan memahami suatu konsep diakibatkan oleh ketidakmampuan untuk menghubungkan pengetahuan baru dengan pengetahuan sebelumnya ataupun belum memiliki pengetahuan awal ${ }^{[13]}$. Pengetahuan peserta didik dinilai baik apabila dapat menjelaskan hubungan fenomena kimia yang umumnya bersifat abstrak (penyelesaian masalah) melalui tingkatan makroskopis, sub-mikroskopis, dan simbolik dalam menjawab pertanyaan pada Lembar Kegiatan dan Lembar Kerja ${ }^{[22]}$. Rerata kriteria hasil analisis Lembar Kegiatan dan Lembar Kerja berturutturut berada pada kriteria tinggi dan cukup tinggi.
Hal ini menunjukkan bahwa tingkat keefektifan modul larutan elektrolit dan nonelektrolit berorientasi chemistry triangle masih berada pada kategori sedang dalam meningkatkan hasil belajar peserta didik sesuai dengan hasil rerata analisis isian modul cukup tinggi (sedang).

Level makroskopik dalam penggunaan modul ini dilakukan pada tahap mengamati dan mengumpulkan data melalui percobaan atau mengamati gambar pada modul seperti kelarutan zat, kekuatan nyala lampu, dan jumlah gelembung yang muncul. Level simbolis ditampilkan melalui lambang ion positif dan ion negatif jika zat dimasukkan ke dalam air. Zat yang tidak mengion juga dilambangkan dengan rumus molekulnya. Level mikroskopik menuntut peserta didik untuk berfikir abstrak. Proses timbulnya gelembung dan nyala lampu yang diakibatkan oleh perpindahan elektron. Peserta didik harus mampu membayangkan arah perpindahan elektron dan sumber arus yang digunakan. Elektron mengalir dari anoda ke katoda yang telah dihubungkan dengan arus listrik searah (DC). Level simbolis akan menampilkan persamaan reaksi pengionan $\mathrm{NaCl}$ di dalam air menjadi $\mathrm{Na}^{+}$dan $\mathrm{Cl}^{\text {. }}$. Modul menampilkan level submikro dengan ilustrasi bentuk masing-masing zat yang mengion, baik pada tahap mengamati atau rangkuman materi.

Peserta didik kelas eksperimen mengikuti langkah pembelajaran lebih terorganisir karena dilengkapi Lembar Kegiatan dan Lembar Kerja berbasis pendekatan saintifik. Peningkatan hasil belajar peserta didik dapat mengacu pada Lembar Kegiatan dan Lembar Kerja yang dikerjakan. Hal ini memungkinkan guru mengetahui upaya peserta didik memproses pengetahuannya berdasarkan cara peserta didik memberikan jawabannya. Peserta didik umumnya kesulitan pada level submikro tentang menentukan jumlahion pada masing-masinglarutan yang diujikan. Penyeleksian ini membutuhkan pengetahuan awal mengenai ikatan kimia dan sistem periodik pada level sub-mikroskopis. Hal yang patut diperhatikan dalam penggunaan modul larutan elektrolit dan nonelektrolit berorientasi chemistry triangle ialah alokasi waktu pembelajaran karena setiap level yang dibahas secara detail membutuhkan lebih banyak waktu.

Peserta didik kelas kontrol mengalami kesulitan dalam penemuan konsep. Hal ini disebabkan oleh ketiadaan Lembar Kegiatan dan Lembar Kerja. Materi larutan elektrolit tidak dipaparkan secara detail dan digabung pada $\mathrm{Bab}$ yang sama dengan materi reaksi redoks. Buku yang biasa digunakan peserta didik memuat latihan berupa Uji Kompetensi yang juga digabung dengan materi reaksi redoks. Data yang didapat dari kelas kontrol digunakan untuk memberikan penguatan (validitas eksternal) atas kesimpulan yang ditarik pada penelitian ini ${ }^{[23]}$.

\section{SIMPULAN}

Kesimpulan dari hasil penelitian ini yaitu modul larutan elektrolit dan nonelektrolit berorientasi chemistry triangle efektif meningkatkan hasil belajar 
peserta didik kelas X MIA SMAN 15 Padang. Tingkat keefektifan modul berada pada tingkat sedang dengan $N$-gain senilai 0,46 . Hal ini ditunjang oleh hasil uji hipotesis t' dengan menolak $\mathrm{H}_{0}$ karena nilai $\mathrm{t}_{\text {hitung }}(4,20)>\mathrm{t}_{\text {tabel }}(1,667)$ pada taraf nyata 0,05 .

\section{REFERENSI}

1. Latisma. Evaluasi Pembelajaran. Padang: UNP Press; 2011.

2. Agus Suprijono. Cooperative Learning Teori dan Aplikasi PAIKEM. Yogyakarta: Pustaka Pelajar; 2010.

3. Hidayat, A Gafur, A. Model Mental Siswa Dalam Memahami Perubahan Wujud Zat. Pengelolaan Dan Pemanfaatan Sumber Belajar Di Sekolah Tinggi Pariwisata Ampta Yogyakarta. Jurnal Inovasi Teknologi Pendidikan. 2015;2(1): 1-15.

4. Mulyasa. Pengembangan Dan Implementasi Kurikulum 2013. Bandung: PT Remaja Rosdakarya; 2013.

5. Purwaningtyas, R., Ashadi, \& Suparmi. Jurnal Pendidikan Sains Universitas Muhammadiyah Semarang. 2014, 02(01).

6. Wena. Strategi Pembelajaran Inovatif Kontemporer. Jakarta: Bumi Aksara; 2009.

7. Farida, I. The Importance Of Development Of Representational Competence In Chemical Problem Solving Using Interactive Multimedia. "Challenging Science Education In The Digital Era” (P. 262). Bandung: The Third International Seminar On Science Education. 2016;(November 2009).

8. Hidayati Kardena. Pengembangan Modul Berorientasi Chemistry Triangle Pada Materi Larutan Elektrolit Dan Non Elektrolit Untuk Pembelajaran Kimia Kelas X Tingkat SMA/MA. Skripsi. Universitas Negeri Padang; 2017.

9. Sari, D. R., Hardeli, \& Bayharti. 2018. Development of Chemistry Triangle Oriented Module on Topic of Reaction Rate for Senior High School Level Grade XI Chemistry Learning . Development of Chemistry Triangle Oriented Module on Topic of Reaction Rate for Senior High School Level Grade XI Chemis. ICOMSET, 335. https://doi.org/10.1088/1757899X/335/1/012105.

10. Chittleborough GD, Treagust DF, Mocerino M. Constraints to the development of first year university chemistry students ' mental models of chemical phenomena. 1998;(1982):43-50.

11. Hanif N, Sopandi W, Kusrijadi A. Analisis Hasil Belajar Level Makroskopik, Submikroskopik, Dan Simbolik Berdasarkan Gaya Kognitif Siswa Sma Pada Materi Pokok Sifat Koligatif Larutan. J Pengajaran MIPA. 2013;18(1):116-23.

12. Latisma DL, Kurniawan W, Seprima S, Nirbayani SE, Ellizar E, Hardeli H. Effect of Chemistry Triangle Oriented Learning Media on Cooperative, Individual and Conventional Method on Chemistry Learning Result. ICOMSET. 2018;335:0-7.
13. Trianto. Mendesain Model Pembelajaran Inovatif Progresif. Jakarta: Kencana Prenada Media Group; 2003.

14. Supardi. Sekolah Efektif: Konsep Dasar dan Praktiknya. PT. Raja Grafindo Persada; 2013.

15. Alfriani A, Hutabri E. Kepraktisan Dan Keefektifan Modul Pembelajaran Bilingual Berbasis Komputer. Jurnal Kependidikan. 2017;1(1):12-23.

16. Hosnan. Pendekatan Saintifik dan Kontekstual dalam Pembelajaran Abad 21. Bogor: Ghalia Indonesia; 2014.

17. Sugiyono. Metode Penelitian Pendidikan. Bandung: CV. Alfabeta; 2010.

18. Hake. Analyzing Change/Gain Score. USA: Indiana University; 1999.

19. Riduwan. Belajar Mudah Penelitian untuk Guru, Karyawan dan Peneliti Pemula. Bandung: Alfabeta 2015.

20. Sudjana. Media Statistika Edisi Ke-6. Bandung: PT. Tarsito Bandung; 2005.

21. Wahyuni, M. D., \& Hardeli. Pengembangan Modul Berorientasi Chemistry Triangle Pada Materi Sistem Koloid Untuk Pembelajaran Kimia Kelas Xi Tingkat SMA/MA. Jurnal of Multidisciplinary Research And Development,. 2019;162-71.

22. Jansoon N, Coll RK. Understanding Mental Models of Dilution in Thai Students. IJESE. 2009;4(2):147-68.

23. Nazir. Metode Penelitian. Jakarta: Ghalia Pustaka; 2009. 